\title{
Modelling and Simulation of Machining Attributes in dry Turning of Aircraft Materials Nimonic C263 using CBN
}

\author{
Srinivasan Senthil Kumar ${ }^{1}$, Moranahalli Ponnusamy Sudeshkumar ${ }^{2}$, Chakaravarthy Ezilarasan ${ }^{3}$, \\ Sivaprakasam Palani ${ }^{4}{ }^{*}$ (D), and Jayaseelan Veerasundaram ${ }^{5}$ (D) \\ ${ }^{1}$ Department of Mechanical Engineering, RMK College of Engineering and Technology, Chennai, India \\ 2 Department of Mechanical Engineering, Shreenivasa Engineering College, Dharmapuri, India \\ ${ }^{3}$ Center for Materials Research, Chennai Institute of Technology, Chennai, India \\ ${ }^{4}$ Department of Mechanical Engineering, College of Electrical and Mechanical Engineering, Center of Excellence-Nano \\ Technology, Addis Ababa Science and Technology University, Addis Ababa, Ethiopia \\ ${ }^{5}$ Department of mechanical Engineering, Prathyusha Engineering College, Chennai, India
}

Received: 23 August 2021 / Accepted: 14 November 2021

\begin{abstract}
In the current scenario, machinability of the super alloys is of greater importance in an aircraft turbine engine and land-based turbine applications owing to its superior properties. However, the machinability of these alloys is found to be poor owing to its inherent properties. Hence, a predictive model has been developed based on DEFORM 3D to forecast the machining attributes such as cutting force and insert's cutting edge temperature in turning of Nimonic C263 super alloy. The dry turning trials on Nimonic C263 material were carried out based on L27 orthogonal array using CBN insert. Linear regression models were developed to predict the machining attributes. Further, multi response optimization was carried out based on desirability approach for optimizing the machining attributes. The validation test was carried out for optimal parameter values such as cutting speed: $117 \mathrm{~m} / \mathrm{min}$, feed rate: $0.055 \mathrm{~mm} / \mathrm{rev}$ and depth of cut: $0.25 \mathrm{~mm}$. The minimum cutting force of $304 \mathrm{~N}$ and insert's cutting edge temperature of $468^{\circ} \mathrm{C}$ were obtained at optimum level of parameters. The predicted values by FEA and linear regression model were compared with experimental results and found to be closer with minimum percentage error. The minimum percentage error obtained by FEA and linear regression model for the machining attributes (cutting force, temperature) as compared with experimental values were $(0.32 \%, 0.23 \%)$ and $(2.34 \%, 1.63 \%)$ respectively.
\end{abstract}

Keywords: CBN / Nimonic C263 / DEFORM 3D / Taguchi / regression model / cutting force temperature at insert edge

\section{Introduction}

High strength alloy Nimonic C263 has been widely used in many crucial parts of aircraftin high-temperature environments owing to its excellent mechanical properties, fatigue strength and creep properties. However, it is tough to cut owing to low conductivity, high work hardening rate and this will obstruct the insert movement and results in poor machined surface and adverse change in the insert geometry. Therefore, the machining of this hardened metal is considered as an important one and need to analyse the impact of machining factors on the machining

\footnotetext{
* e-mail: shiva@aastu.edu.et
}

responses so that, the best machining/control factors and their levels can be identified to improve the integrity/ machinability of the machined surface.

The finite element analysis (FEA) can be effectively used to simulate the machining attributes before the actual experiments, therefore the actual experimental cost due to the noteless impact of machining factors can be avoided. The numerical modelling in metal cutting has been progressed significantly to model the machining factors. In the current trend, there is requirement to predict the machining characteristics in $3 \mathrm{D}$ than $2 \mathrm{D}$, however, there are many challenges in the prediction of the machining characteristics using 3D like more plastics deformations localized in minimum areas, comples interface of tool and workpiece and more geomentrical boundary changes [1]. 
The finite element analysis has been utilized in the past decades to improve the product quality and also there is need to develop FEA model to make large number of outputs with minimum error. Further, the simulation using FEA has provided the facility to vary the geomentry and boundary conditions to study the deformation patterns in detail [2]. Pradhana et al. [3] conducted turning experiments on titanium alloy and the experimentally observed results were compared with the predicted values by DEFORM 3D. They have considered the tool and workpiece as rigid and plastic respectively. The mesh size and element type for tool and workpiece was considered as 25,000 and tetra-hedral respectively.

Satyanarayana et al. [4] developed an FEA model to predict the factors in the turning of Inconel 718 . The predicted FEA values and experimental trail values were compared and found to be negligible variations. Hence DEFORM 3D can be used as an efficient tool to simulate and model the machining process. Uma et al. [5] stated that the analyses of the impact of the controlling factors experimentally in the machining processes are tough and costly, therefore the DEFORM 3D was used as a tool to simulate the machining attributes in turning of Inconel 718. The FEA predicted values very well agreed with the experimental values. Hence, they have concluded that the FEA approach is time-consuming and reduces the experimental trial cost.

Simulation of the cutting forces were carried out in turning Inconel 718 using ABAQUS and the simulated values are agreed well with experimental results. Simulated force is useful to judge the cutting process such as the impact of machining factors on the machining attributes, formation of chip tool wear etc. [6].

The residual stress and surface changes after machining affect badly the life of the part, therefore these are all to be predicted before actual machining to avoid machining and material cost. FEA model is developed to forecast the residue stress and alteration of machined surface in turning inconel 718 and validated with the experimental values. The thermal load was found to be a predominant factor in the generation of residual tensile stress [7]. The control factors such as speed, feed rate, depth of cut and insert materials are considered as main factors to decide the machinability of any alloy. Carbide, ceramic and boron nitride insert materials are used in machining the alloy however, the Cubic Boron Nitride CBN inserts is being used to machine the superalloys due to great hardness at high temperature. CBN also has demerits like tool cracking owing to brittleness and difficulty of chip breaking. However, the CBN inserts are recommended to utilize at high cutting speed to make better the surface finish. The increase in the level of cutting speed has affected the crater and wear of flank majorly in turning the Inconel 718 using PCBN insert, Therefore, identifying the level of cutting speed to machine the superalloys with high integrity using CBN insert is a crucial one [8].

PCBN inserts were being used to cut high hardness alloys owing to their great hardness at elevated temperature, however, it has demerits such as tool cracking owing to brittleness and difficulty of chip breaking The mechanisms such as adhesion, diffusion, chemical, and their combinations were observed in machining the superalloys using PCBN insert [9].
Li et al. [10] conducted a turning experiment on superalloy GH4169 alloy using PCBN and they have identified wear on the flank and rake face with very poor chip break. The wear of the insert was formed in terms of groove wear and adhesive wear. The rate of wear was reduced as the coolant pressure increased.

Machining behaviour on many superalloys have been discussed by many researchers, however, there is no adequate research on Nimonic C263 alloy in dry turning using $\mathrm{CBN}$ inserts at high-speed condition. Moreover, the CBN insert was found to be effective in improving the machining characteristics of superalloys, therefore, the correct choice of parameters in turning superalloys using CBN inserts must be found out. Although CBN is the superior insert to turn superalloys, still there is a need of analyzing the impact of machining factors using CBN on turning the Nimonic C263 alloy. The study on its machinability at high speed with CBN was not carried out adequately earlier by previous researchers.Hence, the present study investigates the impact of factors on cutting force, the temperature at insert edge, in turning Nimonic C263 to get improved machinability.

\section{Materials and methods}

Nimonic C263 alloy was used as a workpiece with $70 \mathrm{~mm}$ diameter. The chemical composition and mechanical properties of the Nimonic C263 can be found [11]. Among the tool materials, the $\mathrm{CBN}$ insert has a higher hot hardness, high thermal conductivity. CBN insert can hold the cutting edge for a prolonged period. CBN insert is employed at a high cutting speed and it facilitates improved surface finish. In this research work, CBN inserts made by Sandvik with the specification CNGA 120408S01030A, 7025 Grade, was chosen. The force and temperature at the insert edge were measured by piezoelectric dynamometer and thermocouple respectively. The control factors such as speed, feed and depth of cut were considered to turn Nimonic C263.

The turning trials were done at dry mode and the L27 orthogonal array (OA) was chosen to do experiment. The machining parameters and their levels are given in Table 1. The results of the experiment are shown in Table 2. The experimental details are shown in Figure 1a and $\mathrm{b}$.

\section{Simulation of machining attributes}

DEFORM 3D was employed to simulate the cutting force and temperature at the insert edge in turning of Nimonic C263. As this material model is not available in the libraryDEFORM 3D, the material model was developed for Nimonic C263.The material was modelled by JohnsonCook (JC) constitute model and it is given in equation (1). The work material can be modelled like elasto-plasic with isotropic hardening and the flow strss can be defined as function of strain, strain rate and temperature based on J-C model [12]. 
Table 1. Machining parameters.

\begin{tabular}{|c|c|c|c|c|c|c|}
\hline \multirow[b]{2}{*}{ S. No } & \multirow[b]{2}{*}{ Control parameters } & \multirow[b]{2}{*}{ Unit } & \multirow[b]{2}{*}{ Symbol } & \multicolumn{3}{|c|}{ Levels } \\
\hline & & & & Level 1 & Level 2 & Level 3 \\
\hline 1 & Cutting speed & $\mathrm{m} / \mathrm{min}$ & $\mathrm{V}$ & 80 & 125 & 190 \\
\hline 2 & Feed rate & $\mathrm{mm} / \mathrm{rev}$ & $\mathrm{S}$ & 0.055 & 0.096 & 0.159 \\
\hline 3 & $\begin{array}{l}\text { Depth of cut } \\
\text { Tool mat }\end{array}$ & $\mathrm{mm}$ & $a_{p}$ & 0.25 & 0.50 & 0.75 \\
\hline
\end{tabular}
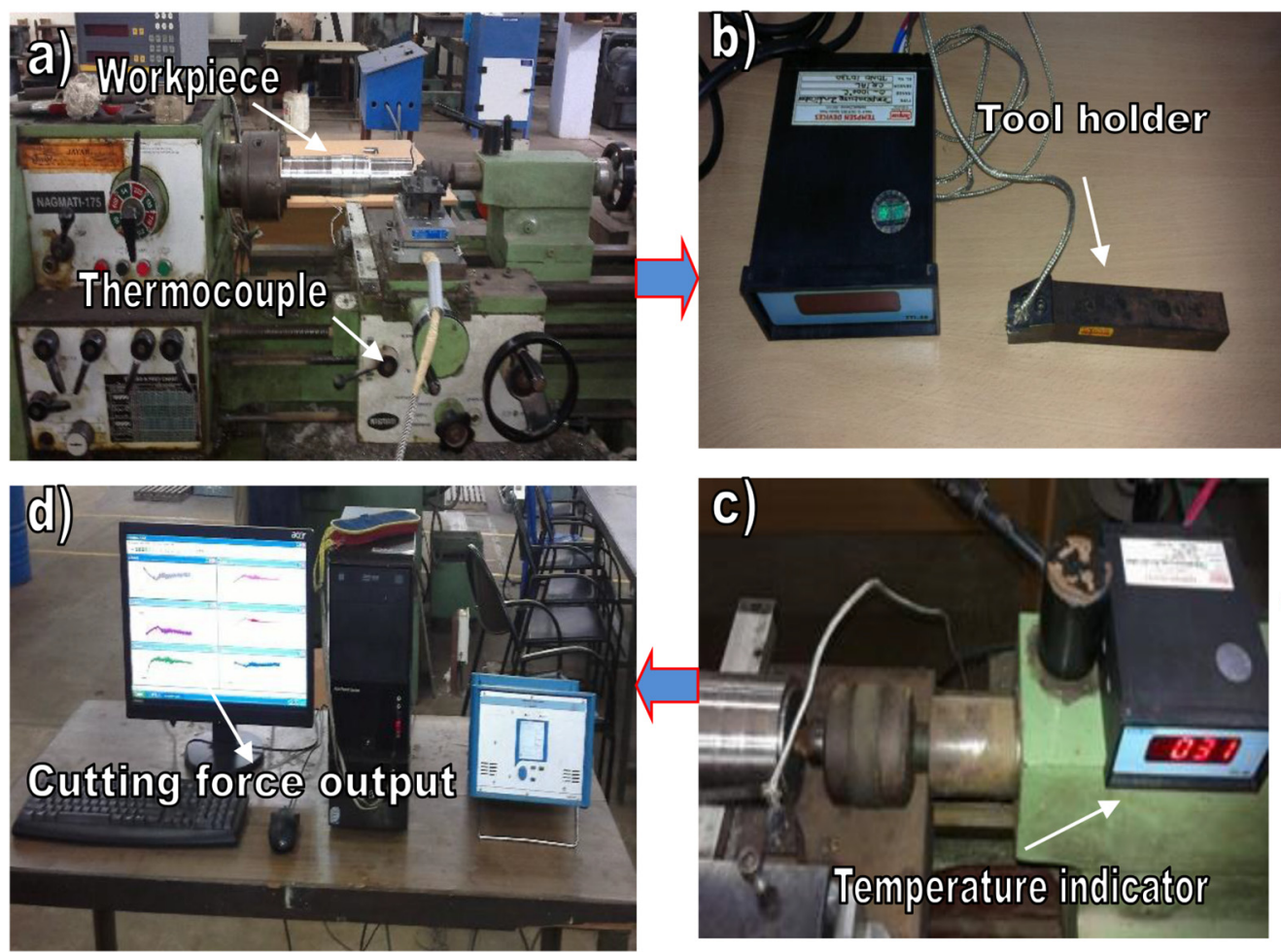

Fig. 1. Experimental details: (a) Experimental Setup, (b) Tool holder, (c) Temperature Measurement, (d) Cutting force Generation/ Output.

The material properties of Nimonic C263 considered to designate the material is given in Table 3 [8]. The basic assumptions considered in this analysis are shown in Table 4 . The meshed image of the insert and workpiece is shown in Figure 2.

$$
\sigma=\left[A+B p^{n}+C \ln \left(\frac{\dot{p}}{\dot{\varepsilon_{0}}}\right)\left[1-\left(\frac{\theta-\theta_{R}}{\theta_{m}-\theta_{R}}\right)^{m}\right] .\right.
$$

The coefficient of friction was considered as a constant and function of time-interface pressure in-between insert and workpiece [13]. The shear friction factor in the range $0.5,0.6$ and 0.7 were chosen to simulate the force and temperature generation at insert's cutting edge during simulation and the simulated values were compared with the experimental results. The simulated results at 0.7 shear friction factor were found to be close to the experimental values. The average percentage error among experimental results and simulated values was found to be $2.34 \%$ and $1.63 \%$ with respect to cutting force and insert's edge temperature.The simulated images of force and insert's edge temperature are illustrated in Figures 3 and 4 respectively. The Coulomb model for frictional force was considered in this FEA analysis and it is shown in equation (2).

$$
F_{t}=\mu F_{n}
$$

where $F_{t}$ is the resulting friction force, $\mu$ is the coefficient of friction, and $F_{n}$ is the normal contact force [13-15].

\section{Linear regression model}

The regression model was developed to evaluate the force, insert's edge temperature and the developed predictive model is shown in equations (3) and (4) respectively. 


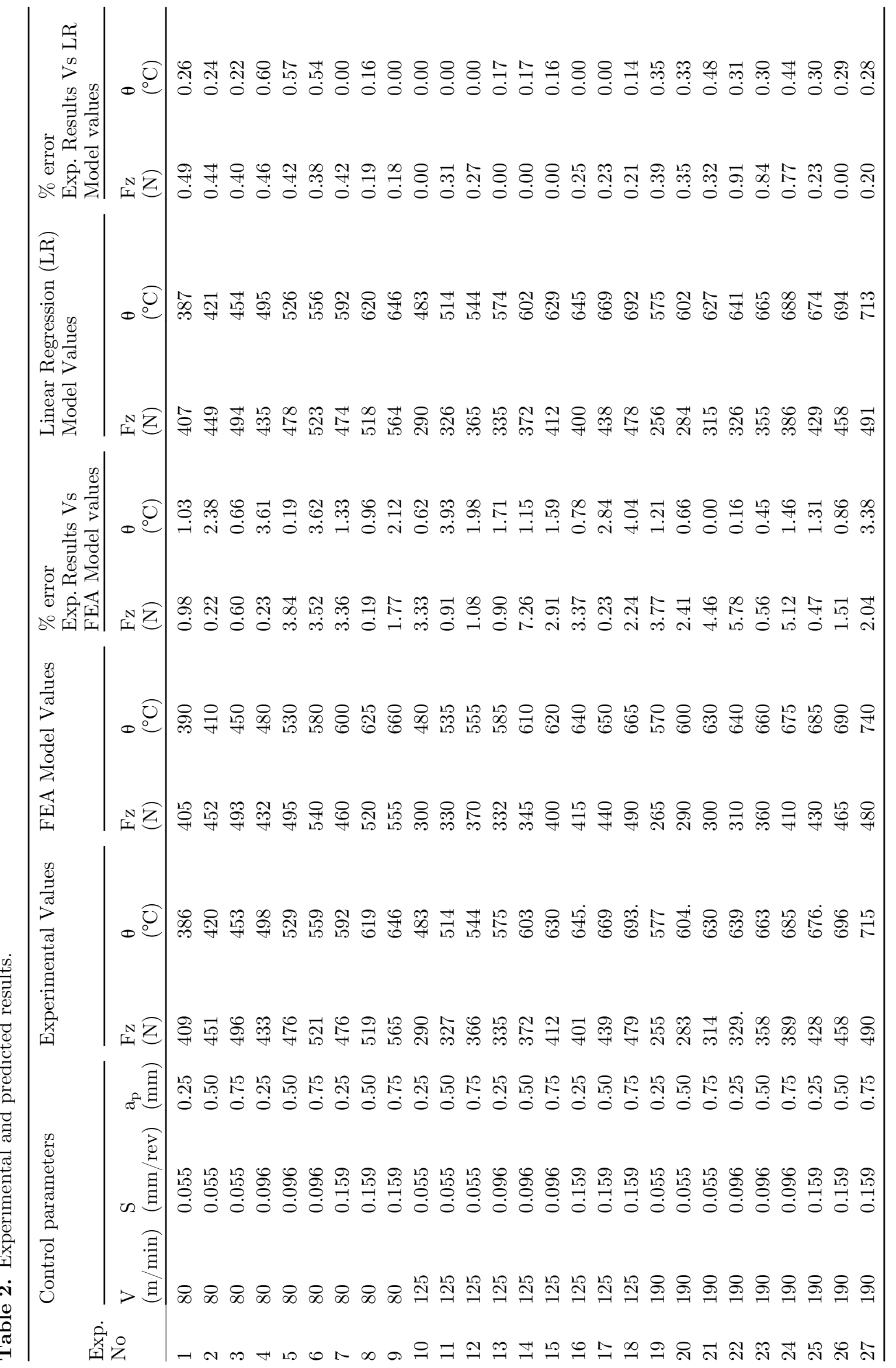




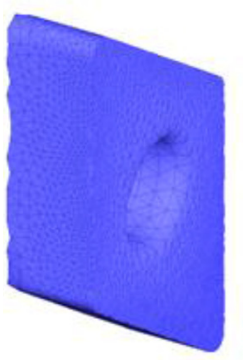

(a)

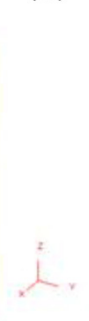

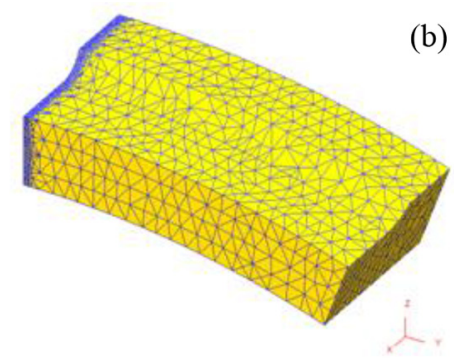

(b)

Fig 2. (a-b). Image of Meshed Insert and Workpiece.

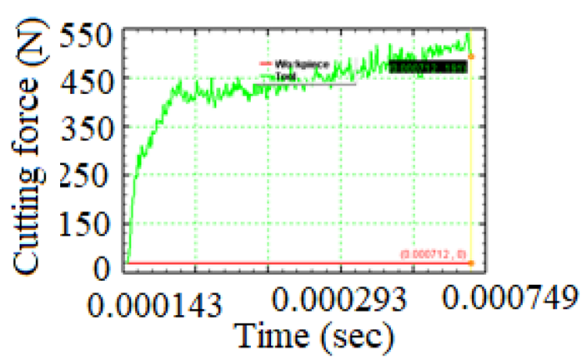

(a)

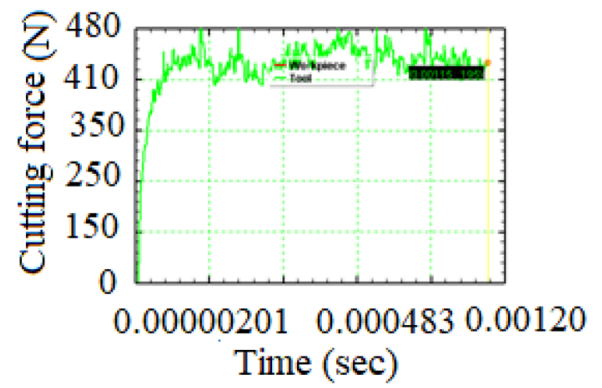

(b)

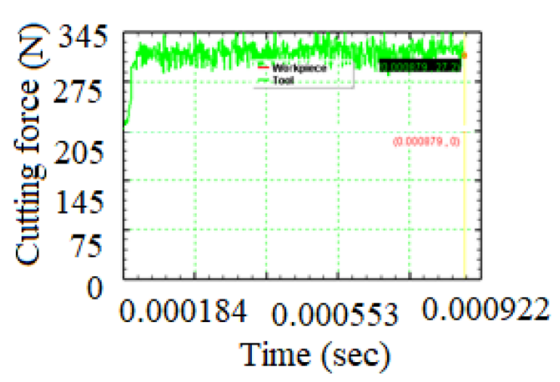

(c)

Fig. 3. Simulated cutting force at various level of parameters. (a) Simulated cutting force at $80 \mathrm{~m} / \mathrm{min}, \mathrm{S}: 0.159 \mathrm{~mm} / \mathrm{rev}$, ap: $0.75 \mathrm{~mm}$. (b) Simulated cutting force at V: $125 \mathrm{~m} / \mathrm{min}, \mathrm{S}: 0.096 \mathrm{~mm} / \mathrm{rev}$, ap: $0.75 \mathrm{~mm}$. (c) Simulated cutting force at (c) V: $190 \mathrm{~m} / \mathrm{min}$, S: $159 \mathrm{~mm} / \mathrm{rev}$, ap: $0.75 \mathrm{~mm}$.

Table 3. Mechanical properties of Nimonic C263.

\begin{tabular}{lll}
\hline S. No & Property & Value \\
\hline 1 & yield strength & $450 \mathrm{MPa}$, \\
2 & Hardening modulus & $1700 \mathrm{MPa}$ \\
3 & Hardening coefficient & 0.65 \\
4 & Strain rate sensitivity coefficient & 0.017 \\
5 & Thermal softening coefficient & 1.3 \\
6 & melting point temperature & $1628 \mathrm{~K}$ \\
\hline
\end{tabular}

Table 4. Assumptions considered in DEFORM 3D analysis.

\begin{tabular}{lll}
\hline S. No & Assumptions & Values \\
\hline 1 & Shear friction factor & 0.6 \\
2 & element type & Tetrahedral \\
3 & Mesh type & Fine \\
4 & No of nodes & 10 \\
5 & Relative mesh for tool/insert & 45000 \\
6 & Relative Mesh for work & 40000 \\
7 & Work piece type & Plastic \& Isotropic \\
8 & Tool Materia & Carbide Insert \\
9 & Environment Temperature & $20^{\circ} \mathrm{C}$ \\
10 & Convection Coefficient & 0.02 \\
11 & Heat transfer coefficient & 45 \\
12 & Number of Simulation steps & 750 \\
13 & Step increment to save & 25 \\
14 & Arc angle to cut & 20 \\
\hline
\end{tabular}



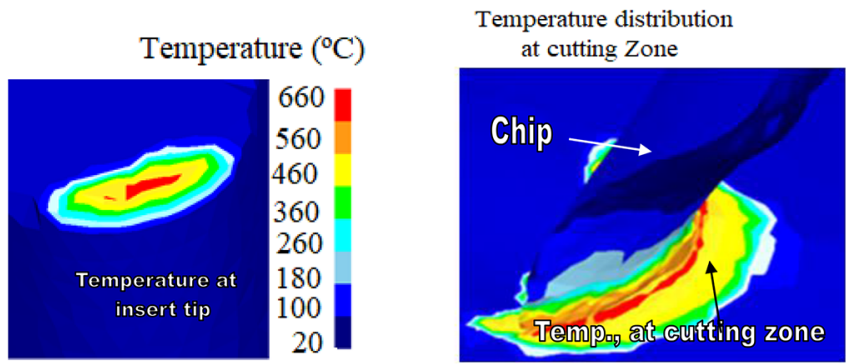

(a)
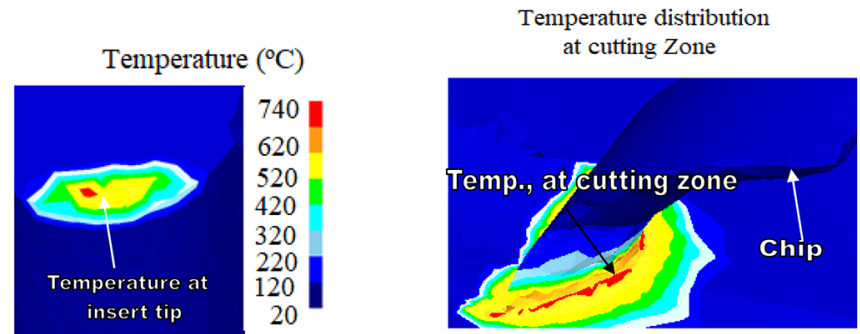

(b)
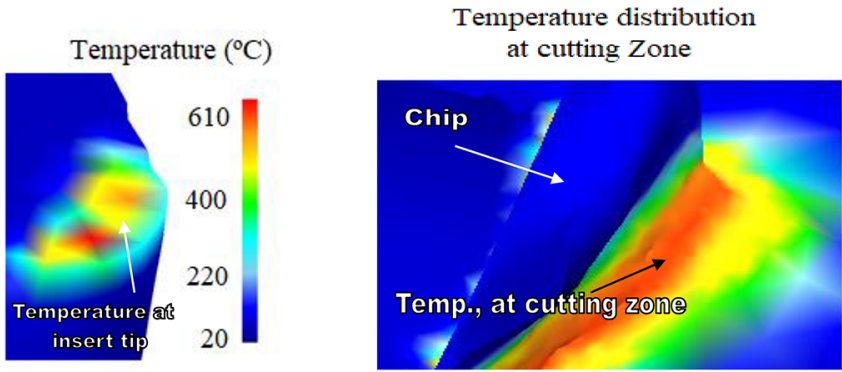

(c)

Fig. 4. Simulated temperature at (a) V-80 m/min, S- $-0.159 \mathrm{~mm} / \mathrm{rev}$, ap- $0.75 \mathrm{~mm}$, (b) V-125 m/min, S-0.096 mm/rev, ap-0.75 mm, (c) $\mathrm{V}-190 \mathrm{~m} / \mathrm{min}, \mathrm{S}-159 \mathrm{~mm} / \mathrm{rev}$, ap- $0.75 \mathrm{~mm}$.

$$
\begin{aligned}
& \text { Cutting force } F_{z},(\mathrm{~N})=+785.96-6.85 * \mathrm{~V}-660.52 * \mathrm{~S} \\
& +197.69 * \mathrm{a}_{\mathrm{p}}+9 * \mathrm{~V} * \mathrm{~S}-0.50 * \mathrm{~V} * \mathrm{a}_{\mathrm{p}} \\
& \quad+51.38 * \mathrm{~S} * \mathrm{a}_{\mathrm{p}}+0.01 * \mathrm{~V}^{2}+2595 * \mathrm{~S}^{2} \\
& \quad+13.33 * \mathrm{a}_{\mathrm{p}}^{2}
\end{aligned}
$$

Temperature at insert edge $\Theta\left({ }^{\circ} \mathrm{C}\right)=-71.30+4.01 * \mathrm{~V}$

$$
\begin{aligned}
& +3791 * \mathrm{~S}+173 * \mathrm{a}_{\mathrm{p}}-9.02 * \mathrm{~V} * \mathrm{~S}-0.27 * \mathrm{~V} \\
& \quad * \mathrm{a}_{\mathrm{p}}-247 * \mathrm{~S} * \mathrm{a}_{\mathrm{p}}-6.46637 \mathrm{E}-003 * \mathrm{~V}^{2} \\
& \quad-5244 * \mathrm{~S}^{2}-4.44 * \mathrm{a}_{p}^{2} .
\end{aligned}
$$

Tables 5 and 6 show ANOVA for force and insert's edge temperature. It is observed that, the feed rate was found to be predominant factor in effecting the cutting force and temperature at insert edge followed by other factors.

\section{Optimization of controlling parameters based on desirability approach}

The multi-response optimization of factors is done based on desirability approach [16]. Figure 5 shows the histogram of the desirability and the desirability value for both machining parameters and machining attributes are shown. The goal-setting and the limits for the optimization are given in Table 7 . The best solution for multi-response optimization is given in Table 8 .

\section{Effect of process parameters on machining attributes}

\subsection{Parameters'effect on $F_{z}$}

The cutting force is the main character in the turning of superalloys. The magnitude of the force is pivotal as it is connected to part accuracy and machinability etc. and also it depends on the tool material and tool geometry majorly [17]. In this article, the impact of the controlling factors on the cutting force during dry turning the Nimonic C263 using a CBN tool was carried out. Figure $6 \mathrm{a}-\mathrm{c}$ illustrates the contour graph for cutting force and depicts the impact of the controlling factors on the cutting force and it is inferred that the range of cutting force intends to escalate as the level of speed decreases, for all levels of depth of cut. The interaction effect of controlling factors on the force is shown in Figure $7 \mathrm{a}-\mathrm{c}$. 
Table 5. ANOVA for cutting force $(\mathrm{Fz})$.

\begin{tabular}{llllll}
\hline Source & $\begin{array}{l}\text { Degrees of } \\
\text { Freedom (DOF) }\end{array}$ & $\begin{array}{l}\text { Sequence } \\
\text { sum of the squares }\end{array}$ & $\begin{array}{l}\text { Adj } \\
\text { mean square }\end{array}$ & F-value & \% contribution \\
\hline Model & 9 & $1.705 \mathrm{E}+005$ & 18949.29 & 58.86 & \\
$\mathrm{~V}$ & 1 & 56779.10 & 56779.10 & 176.36 & 32 \\
$S$ & 1 & 66824.11 & 66824.11 & 207.57 & 38 \\
$\mathrm{a}_{\mathrm{p}}$ & 1 & 24552.70 & 24552.70 & 76.26 & 14 \\
$\mathrm{~V}{ }^{*} S$ & 1 & 8682.79 & 8682.79 & 26.97 & 5.09 \\
$\mathrm{~V}^{*} \mathrm{a}_{\mathrm{p}}$ & 1 & 582.85 & 582.85 & 1.81 & 0.3418 \\
$S^{*} \mathrm{a}_{\mathrm{p}}$ & 1 & 5.78 & 5.78 & 0.018 & 0.0032 \\
$\mathrm{~V}^{2}$ & 1 & 18283.39 & 18283.39 & 56.79 & 10.38 \\
$S^{2}$ & 1 & 341.33 & 341.33 & 1.06 & 0.19 \\
$\mathrm{a}_{\mathrm{p}}{ }^{2}$ & 1 & 4.17 & 4.17 & 0.013 & 0.0023 \\
Residual & 17 & 5473.02 & 321.94 & & 3.10 \\
Total & 26 & $1.760 \mathrm{E}+005$ & & & 100 \\
\hline
\end{tabular}

Table 6. ANOVA for temperature at the cutting edge $(\theta)$.

\begin{tabular}{llllll}
\hline Sources & DOF & $\begin{array}{l}\text { Seq } \\
\text { sum of the squares }\end{array}$ & $\begin{array}{l}\text { Adj } \\
\text { mean square }\end{array}$ & F-value & \% contribution \\
\hline Model & 9 & $2.009 \mathrm{E}+005$ & 22320 & 70.08 & \\
$\mathrm{~V}$ & 1 & 74185.28 & 74185 & 232.92 & 35.9599 \\
$S$ & 1 & 91248.04 & 91248 & 286.49 & 44.23075 \\
$\mathrm{a}_{\mathrm{p}}$ & 1 & 12545.65 & 12545 & 39.39 & 6.081265 \\
$\mathrm{~V}$ & 1 & 8718.24 & 8718 & 27.37 & 4.226001 \\
$\mathrm{~V}^{*} \mathrm{a}_{\mathrm{p}}$ & 1 & 168.04 & 168 & 0.53 & 0.081454 \\
$S^{*} \mathrm{a}_{\mathrm{p}}$ & 1 & 134.43 & 134 & 0.42 & 0.065162 \\
$\mathrm{~V}^{2}$ & 1 & 2123.07 & 2123 & 6.67 & 1.029118 \\
$S^{2}$ & 1 & 1393.38 & 1393 & 4.37 & 0.675414 \\
$\mathrm{a}_{\mathrm{p}}{ }^{2}$ & 1 & 0.46 & 0.46 & $1.454 \mathrm{E}-003$ & 0.000223 \\
Residual & 17 & 5414.48 & 318 & & 2.624566 \\
Total & 26 & $2.063 \mathrm{E}+005$ & & & 100 \\
\hline
\end{tabular}

The rate of the cutting force is reduced as the level of speed increase for the lower level of feed and depth of cut as shown in Figure $7 \mathrm{a}-\mathrm{b}$. The rate of the cutting force is increased as the level of feed rate and depth of cut escalate as shown in Figure 7c.

The maximum of $526 \mathrm{~N}$ force is generated, at a lower speed and a higher level of depth of cut as shown in Figure 8a. The force seems to increase as the complexity of the cut rises at low cutting speeds. The magnitude of the force is not changed much when the cutting speed at a mid and high level of speed in turning this alloy using CBN insert. The highest of the cutting force of $510 \mathrm{~N}$ at a high level of feed rate and at a lower level of speed is observed as shown in Figure 8b. Whereas the alteration in the range of the force remains constant up to $0.096 \mathrm{~mm} / \mathrm{rev}$ at mid level of cutting speed as shown in Figure 8b.

As the feed rate increases, the cutting force's range increases at all levels of speeds and also the cutting forces were found to be increased at lower and medium speeds due to a developed substantial coefficient of friction in the cutting zone. Turning at a high speed causes the material to soften owing to temperature generation in the conact surface of insert edge and material and the cutting force seems to decrease [18]. The cutting force constituent tends to grow in magnitude with increasing feed and cut depth, as seen in Figure 8c. For deeper cuts and larger feed rates, the cutting force is as high as $508 \mathrm{~N}$ as seen in Figure 8c. This is due to the cutting edge being damaged; causing an abrasion among the tool edge and the work portion exterior, resultant in increased flank wear and higher cutting force is caused [19].

\subsection{Effect of machining parameters on temperature at insert edge}

Temperature generation at the cutting zone plays a vital role and it would affect the machined surface as well as the cutting edge. Therefore, the temperature generation at the cutting edge should be controlled and need to identify the impact of controlling factors on machining Nimonic C263 


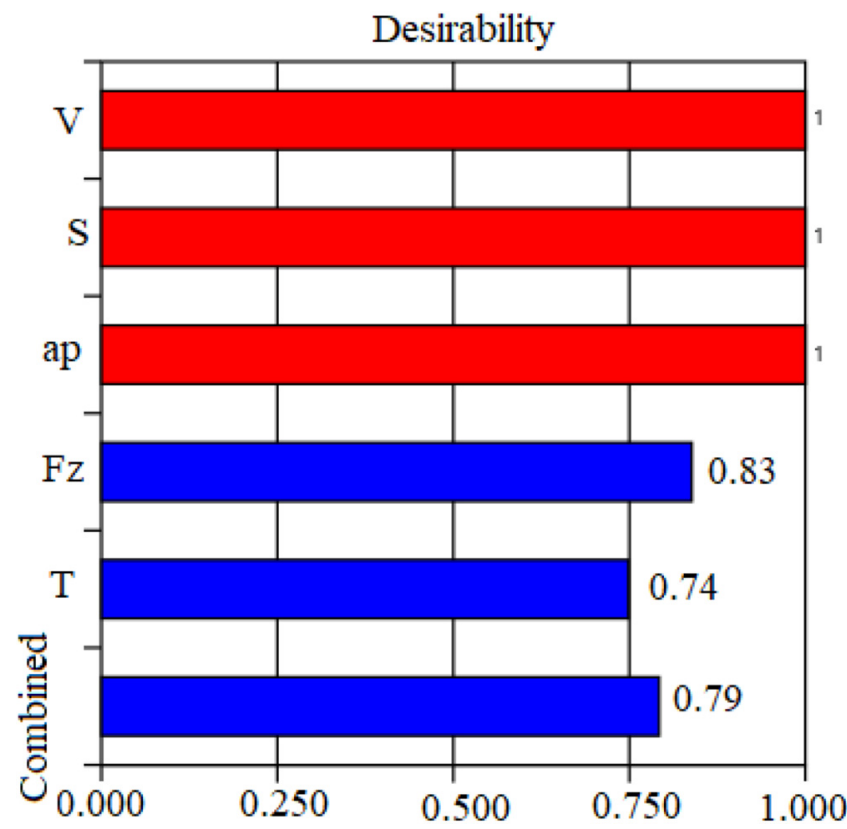

Fig. 5. Histogram.

using CBN insert. Figure 9a and b illustrates the contour graph for the temperature at the insert edge and depicts the impact of the controlling factors on it and it is noted that the magnitude of temperature at the insert edge intends to increase as the level of parameters increases. The interaction effect of controlling factors on the temperature at the insert edge is shown in Figure $10 \mathrm{a}-\mathrm{c}$. The alteration of the magnitude of the temperature at the insert edge is increased as the level of all the factors increases and therefore the best choice of the factors is to be found to minimize the temperature distribution in the insert edge. When feed rate and cutting speed are enlarged, it is pragmatic that the cutting-edge temperature increases and the increase in the cutting temperature tends to generate the notch and flank wear [20].
It is also noted that a higher feed rate and cutting rapidity produces a temperature extreme of $705^{\circ} \mathrm{C}$ as shown in Figure 11a. At high speed and feed, adhesion and abrasion may present in the machining zone; it causes the concentration of higher temperature at the cutting edge [20]. A high cutting speed and depth of cut result in a higher surface temperature at the cutting edge, as seen in Figure 11b. When feed rate and cut depth increase, the temperature at the cutting edge tends to rise. For deeper cuts and faster feeding, a maximum temperature of $688^{\circ} \mathrm{C}$ is recorded. The cutting edge's temperature increases as the feed rate, cutting speed, and depth of cut are increased as shown in Figure $11 \mathrm{a}-\mathrm{c}$.

\section{Validation of the experimental results, simulated results and linear regression model results}

The validation tests were done for the optimal parameters such as $V=117 \mathrm{~m} / \mathrm{min}, \quad S=0.055 \mathrm{~mm} / \mathrm{rev}$ and ap- $0.25 \mathrm{~mm}$. The validation test values and the predicted values by FEA and linear regression (LR) model are tabulated in Table 9. From Table 7 , it is identified that the predicted value by FEA is very closer to experimental results than the (LR) model, hence FEA model can be effectively utilized for the prediction of the output and the wastage cost in the actual experiments owing to the unknown impact of controlling factors in turning the Nimonic C263 alloy using CBN insert can be avoided. Further, the experimental values were compared with FEA and LR model values and are all found to be closer to the experimental values. The average \% error among experimental and FEA models for the force and temperature at the edge were observed as $2.34 \%$ and $1.63 \%$ respectively. The average $\%$ error among the experimental and LR model for the force and temperature at the edge were observed as $0.32 \%$ and $0.23 \%$ respectively.

Table 7. Goal sets and limits for optimization.

\begin{tabular}{lllllll}
\hline S. No & Goal & Lower limit & Upper limit & Lower weight & Upper weight & Importance \\
\hline Is in range & 80 & 190 & 1 & 1 & 1 & 3 \\
Is in range & 0.055 & 0.159 & 1 & 1 & 1 & 3 \\
Is in range & 0.25 & 0.75 & 1 & 1 & 3 \\
Minimize & 255 & 565 & 1 & 1 & 3 \\
Minimize & 386 & 715 & 1 & 1 \\
\hline
\end{tabular}

Table 8. Global solution-best.

\begin{tabular}{lllllll}
\hline Number & $\mathrm{V}$ & $\mathrm{S}$ & $\mathrm{a}_{\mathrm{p}}$ & $\mathrm{F}_{\mathrm{z}}$ & $\mathrm{T}$ & Desirability \\
\hline 1 & 117 & 0.055 & 0.250 & 304 & 468 & 0.792 \\
2 & 116 & 0.055 & 0.250 & 305 & 467 & 0.792 \\
3 & 117 & 0.055 & 0.250 & 304 & 469 & 0.792 \\
\hline
\end{tabular}




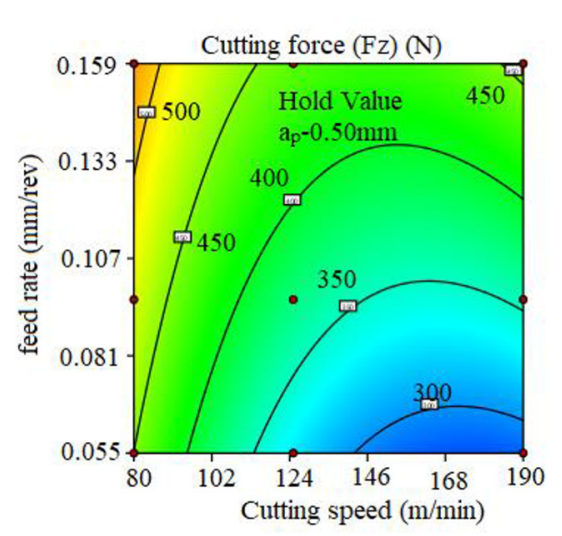

(a)

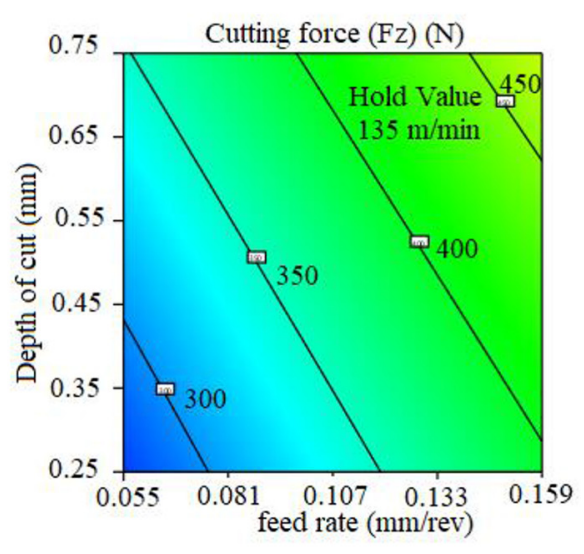

(b)

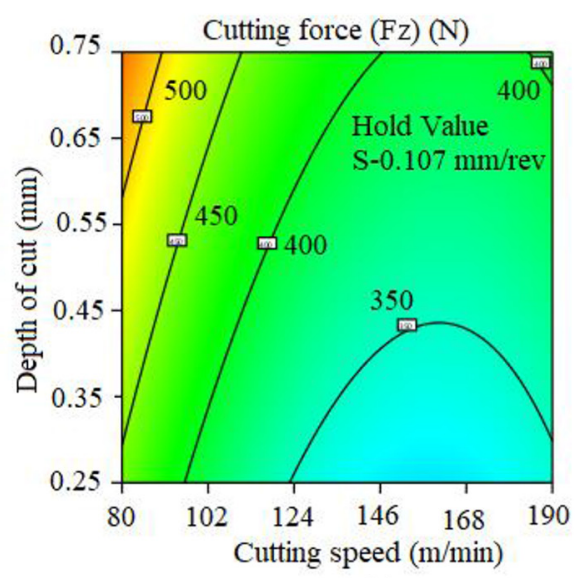

(c)

Fig. 6. Cutting force contour: (a) cutting speed and feed planes at depth of cut of $0.50 \mathrm{~mm}$, (b) feed and depth of cut planes at cutting speed of $135 \mathrm{~m} / \mathrm{min}$, (c) cutting speed and depth of cut planes at feed rate of $0.107 \mathrm{~mm} / \mathrm{rev}$.

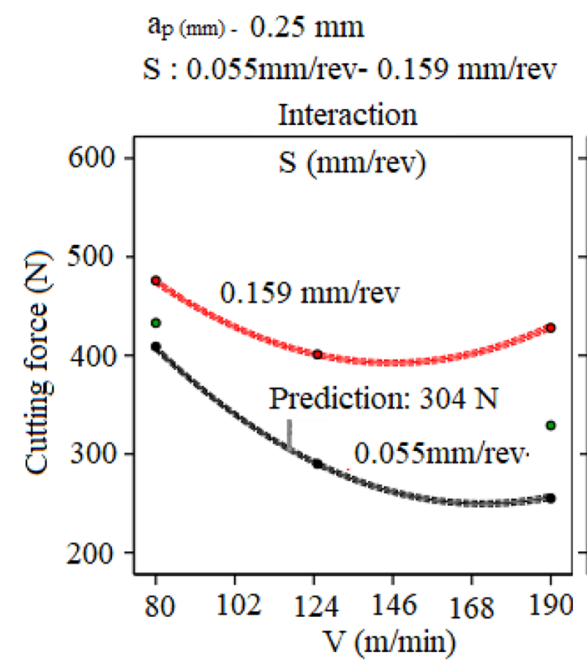

(a)

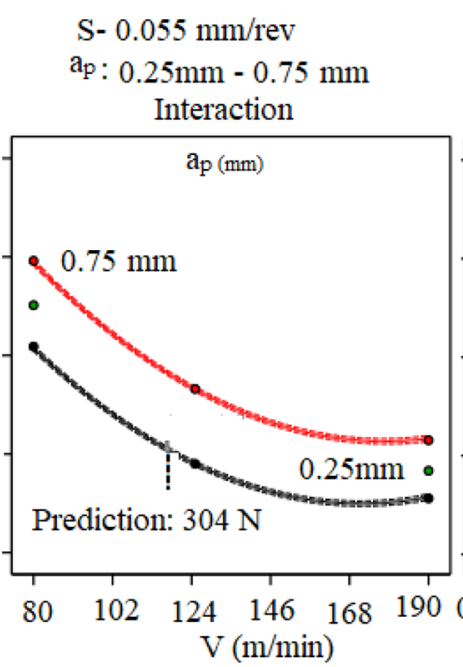

(b)

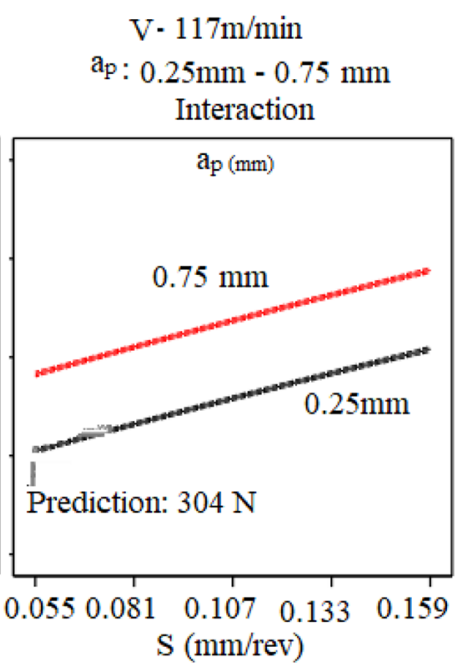

(c)

Fig. 7. Interaction effect of factors on cutting force: (a) Interaction effect of cutting speed and feed rate at depth of cut of $0.25 \mathrm{~mm}$, (b) cutting speed and depth of cut planes at feed rate of $0.055 \mathrm{~mm} / \mathrm{rev},(\mathrm{c})$ interaction effect of feed and depth of cut at cutting speed of $117 \mathrm{~m} / \mathrm{min}$.

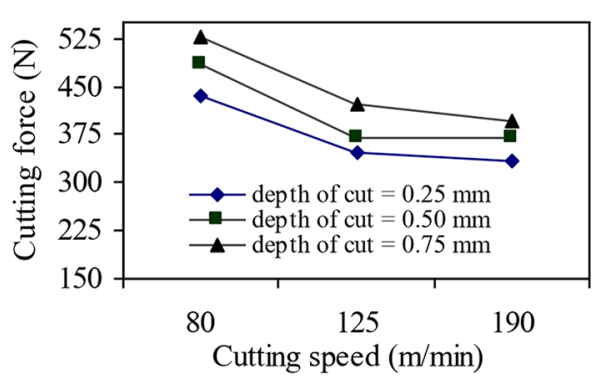

(a)

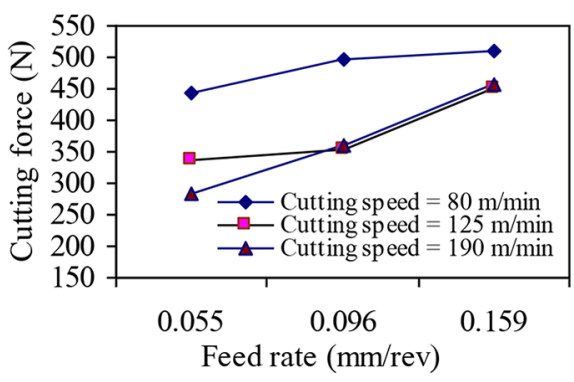

(b)

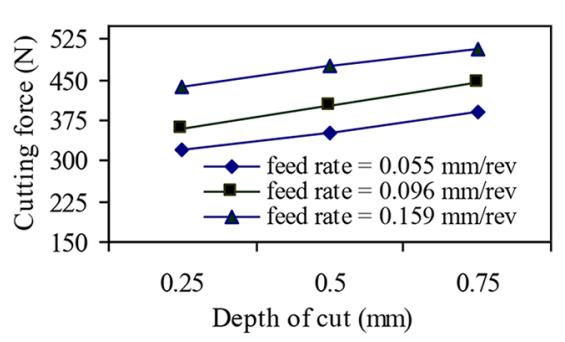

(c)

Fig. 8. Impact of factors on cutting force. (a) Effect of cutting speed at different depths of cut. (b) Effect of feed rate at different cutting speed. (c) Effect of depth of cut at different feed rates. 


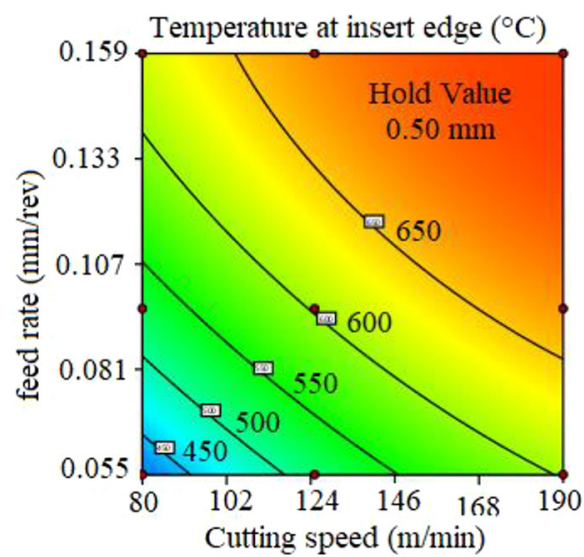

(a)

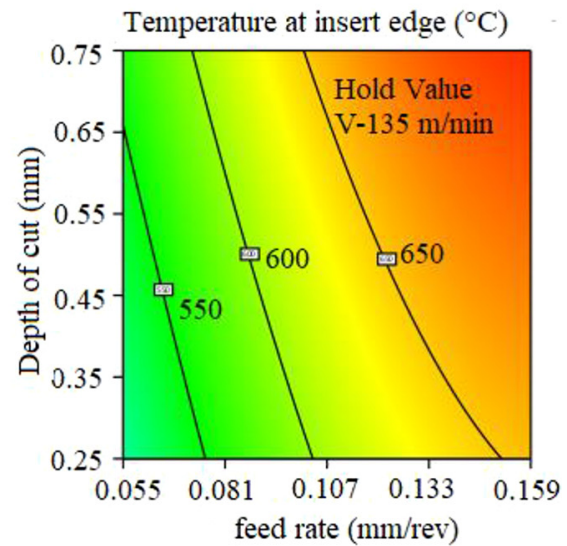

(b)

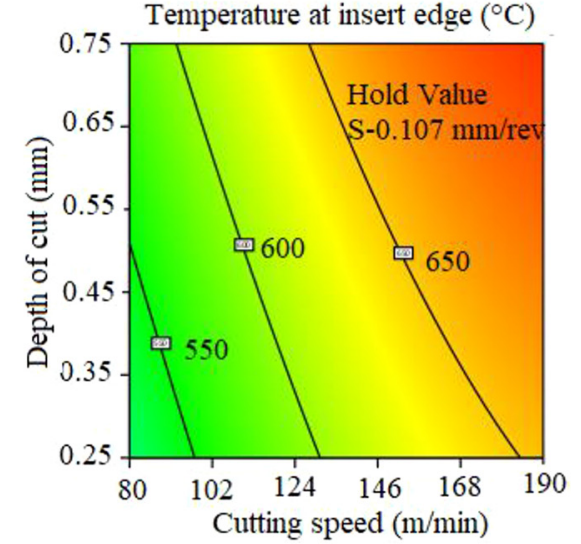

(c)

Fig. 9. Temperature at insert edge contour. (a) Cutting speed and feed planes at depth of cut of $0.50 \mathrm{~mm}$, (b) feed and depth of cut planes at cutting speed of $135 \mathrm{~m} / \mathrm{min}$, (c) cutting speed and depth of cut planes at feed rate of $0.107 \mathrm{~mm} / \mathrm{rev}$.

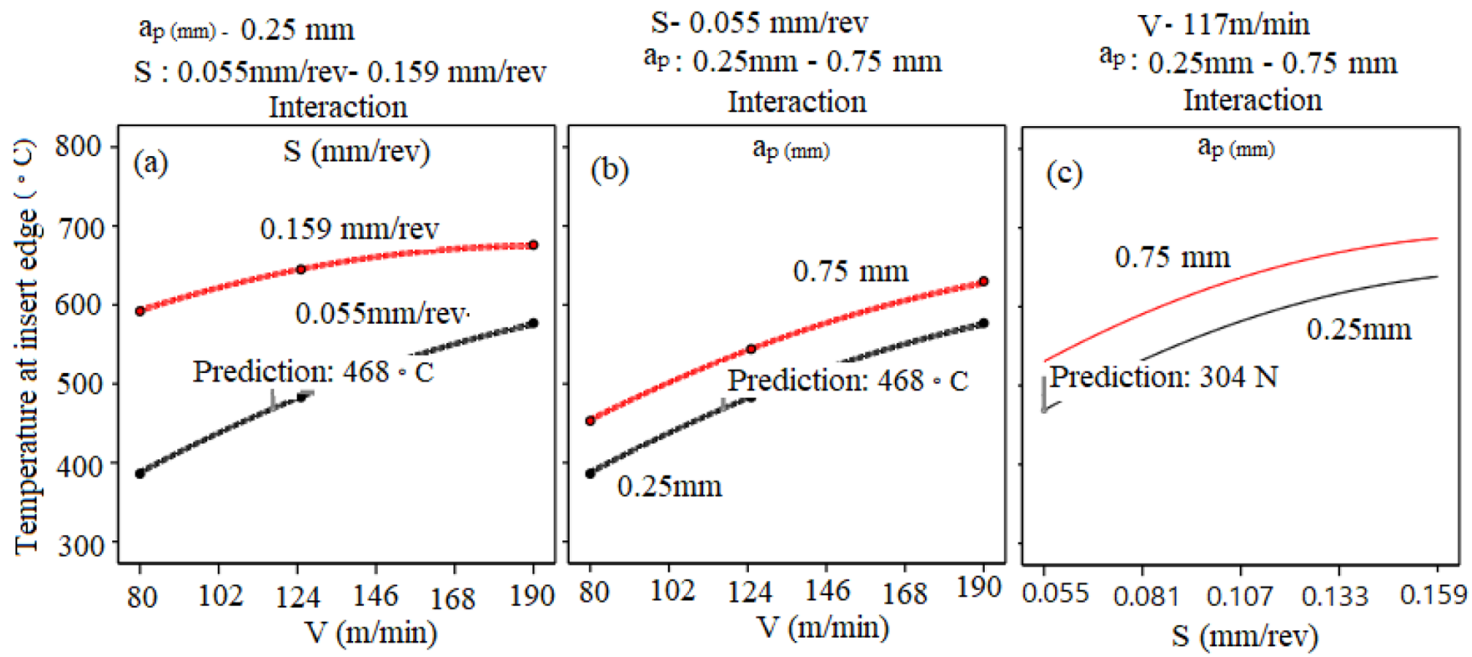

Fig. 10. Interaction effect of factors on temperature at insert edge. (a) Interaction effect of cutting speed and feed rate at depth of cut of $0.25 \mathrm{~mm}$, (b) cutting speed and depth of cut planes at feed rate of $0.055 \mathrm{~mm} / \mathrm{rev}$, (c) interaction effect of feed and depth of cut at cutting speed of $117 \mathrm{~m} / \mathrm{min}$.

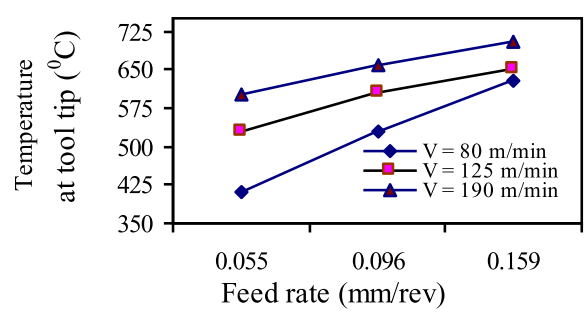

(a)

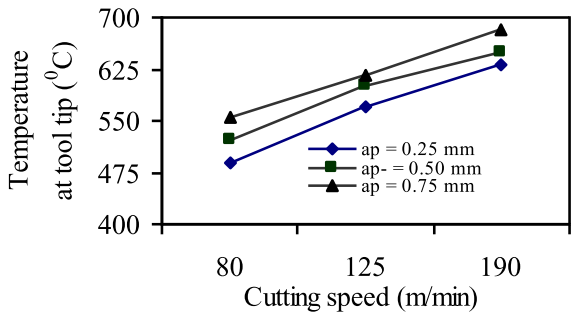

(b)

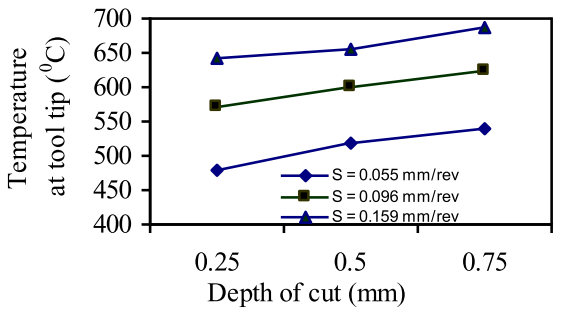

(c)

Fig. 11. Impact of factors on temperature at insert ege. (a) Effect of cutting speed at different depth of cut. (b) Effect of feed rate at different cutting speed. (c) Effect of depth of cut at different feed rate.

Table 9. Confirmation test results.

\begin{tabular}{|c|c|c|c|c|c|c|c|c|}
\hline \multicolumn{3}{|c|}{ Optimum parameters by desirability approach } & \multicolumn{2}{|c|}{$\underline{\text { Experimental values }}$} & \multicolumn{2}{|c|}{$\underline{\text { FEA model predicted }}$} & \multicolumn{2}{|c|}{$\underline{\text { LR model }}$} \\
\hline $\begin{array}{l}\mathrm{V} \\
(\mathrm{m} / \mathrm{min}) \\
\end{array}$ & $\begin{array}{l}\mathrm{S} \\
(\mathrm{mm} / \mathrm{rev})\end{array}$ & $\mathrm{a}_{\mathrm{p}}(\mathrm{mm})$ & $\begin{array}{l}\mathrm{Fz} \\
(\mathrm{N})\end{array}$ & $\begin{array}{l}\theta \\
\left({ }^{\circ} \mathrm{C}\right)\end{array}$ & $\begin{array}{l}\mathrm{Fz} \\
(\mathrm{N})\end{array}$ & $\begin{array}{l}\theta \\
\left({ }^{\circ} \mathrm{C}\right)\end{array}$ & $\begin{array}{l}\mathrm{Fz} \\
(\mathrm{N})\end{array}$ & $\begin{array}{l}\theta \\
\left({ }^{\circ} \mathrm{C}\right)\end{array}$ \\
\hline 117 & 0.055 & 0.25 & 320 & 458 & 317 & 455 & 304 & 468 \\
\hline
\end{tabular}




\section{Conclusion}

- The range of the cutting force is high at the lower speed of $80 \mathrm{~m} / \mathrm{min}$ than at the high cutting speed of $190 \mathrm{~m} / \mathrm{min}$. However, no change in the range of the force at the middle level of speed remarkably.

- A predictive model was developed based on linear regression model to forecast the force and temperature at the insert edge.

- Optimal factors such as V-117 m/min, S-0.055 mm/rev and $a_{p}-0.25 \mathrm{~mm}$ were found in multi-response optimization to get the minimum of force and temperature at the insert edge.

- The statistical analysis of the experimental values shows that the rate of feed and speed, have a notable impact on the cutting force, temperature at the insert edge accompanied by the depth of cut.

- The magnitude of temperature at insert edge is $705^{\circ} \mathrm{C}$ is observed at a higher level feed rate and cutting speed, which is 1.034 times higher than the temperature observed at a high speed and depth of cut.

- The cutting force when turning Nimonic C263 alloy using CBN insert at low cutting speed and high feed rate was predominantly affected. However, no change in the range of cutting force as the feed rate increases from $0.055 \mathrm{~mm} /$ rev to $0.096 \mathrm{~mm} / \mathrm{rev}$ at a middle level of speed.

- DEFORM 3D simulation can be effectively utilized to forecast the cutting force and cutting temperature at the insert edge before the actual experiments, thus the actual machining cost owing to the unknown impact of machining parameters can be avoided.

- The average $\%$ error for force and temperature at insert edge among experimental and forecasted values by linear regression model is $0.32 \%$ and $0.23 \%$ respectively.

- The average $\%$ error for force and temperature at insert edge among experimental and forecasted values by FEA is $2.34 \%$ and $1.63 \%$ respectively.

\section{References}

1. J.M. Rodríguez, J.M. Carbonell, P. Jonsén, Numerical methods for the modelling of chip formation, Arch. Computat. Methods Eng. 27 (2020) 387-412

2. G. Singh, B. Kalita, K.I. Vishnu Narayanan, U.K. Arora, M. M. Mahapatra, R. Jayaganthan, Finite element analysis and experimental evaluation of residual stress of $\mathrm{Zr}-4$ alloys processed through swaging, Metals 10 (2020) 1281

3. M. Swasthik Pradhana, S. Singha, C. Prakasha, G. Krolczykb, A. Pramanikc, C. Iulian Pruncu, Investigation of machining characteristics of hard-to-machine Ti-6Al-4VELI alloy for biomedical applications, J. Mater. Res. Technol. 8 (2019) 4849-4862

4. B. Satyanarayana, M. Dileep Reddy, P. Ruthvik Nitin, Optimization of controllable turning parameters for high speed dry machining of super alloy: FEA and experimentation, Mater. Today: Proc. 4 (2017) 2203-2212
5. U. Maheshwera Reddy Paturi, S. Methuku, S.S. Siripragada, Y. Sangishetty, R. Kumar Gunda, Finite element simulations of machinability parameters in turning of Inconel 718, Mater. Today: Proc. 38 (2021) 2658-2663

6. M. Sandeep Kumar, R. Reddy, V. Vasu, A 3-D simulation and experimental study of cutting forces in turning Inconel718, Mater. Today: Proc. 4 (2017) 9942-9945

7. X. Ren, Z. Liu, A simulation model for predicting surface integrity coupled thermal-mechanical effect in turning of Inconel 718 super alloy, Int. J. Adv. Manuf. Technol. 100 (2019) 1825-1837

8. V. Bushlya, F. Lenrick, A. Bjerke, H. Aboulfadl, M. Thuvander, J.-E. Stahla, R.M. Saoubi, Tool wear mechanisms of PcBN in machining Inconel 718: analysis across multiple length scale, CIRP Ann. Manufactur. Technol. 70 (2021) 73-78

9. W. Fan, W. Ji, L. Wang, L. Zheng, Y. Wang, A review on cutting tool technology in machining of Ni-based super alloys, Int. J. Adv. Manuf. Technol. 110 (2020) 2863-2879

10. L. Li, M. Wu, X. Liu, Y. Cheng, Y. Yu, Experimental study of the wear behavior of PCBN inserts during cutting of GH4169 super alloys under high-pressure cooling, Int. J. Adv. Manuf. Technol. 95 (2018) 1941-1951

11. C. Ezilarasan, V.S. Senthil Kumar, A. Velayudham, Theoretical predictions and experimental validations on machining the Nimonic C-263 super alloy, Simul. Model. Practice Theory 40 (2014) 192-207

12. A. Yildiz Abdullahkurt, S. Yagmur, Finite element simulation of drilling operation and theoretical analysis of drill stresses with the deform-3D, Simul. Model. Practice Theory 104 (2020) 1-17

13. J. Oirere Obiko, F. Madaraka Mwema, M. Oluwatosin Bodunrin, Validation and optimization of cutting parameters for Ti-6Al-4V turning operation using DEFORM 3D simulations and Taguchi method, Manufacturing Rev. 8, (2021) 1-13

14. Y. Liu, J. Li, Z.M. Zhang, X.H. Huand, W.J. Zhang, Experimental comparison of five friction models on thesame test-bed of the micro stick-slip motion system, Mech. Sci. 6 (2015) 15-28

15. A. Kumar Parida, Simulation and experimental investigation of drilling of Ti-6Al-4V alloy, Int. J. Lightweight Mater. Manufact. 1 (2018) 197-205

16. R.K. Bhushan, Multi-response optimization of parameters during turning of AA7075/ $\mathrm{SiC}$ composite for minimum surface roughness and maximum tool life, Silicon (2020). https:/doi.org/10.1007/s12633-020-00640-w

17. M. Erdi Korkmaz, N. Yasar, M. Gunay, Numerical and experimental investigation of cutting forces in turning of Nimonic 80A super alloy, Eng. Sci. Technol. 23 (2020) 664673

18. C. Yao, Z. Zhou, J. Zhang, D. Wu, L. Tan, Experimental study on cutting force of, face-turning Inconel718 with ceramic tools and carbide tools, Adv. Mech. Eng. 9 (2017) 1-9

19. W. Zebala, G. Struzikiewiczand, K. Rumian, Cutting forces and tool wear investigation during turning of sintered nickelcobalt alloy with CBN tools, Materials (2021)

20. E. Kaya, B. Akyüz, Effects of cutting parameters on machinability characteristics of Ni-based superalloys: a review, Open Eng. 7 (2017) 330-342

Cite this article as: Srinivasan Senthil Kumar, Moranahalli Ponnusamy Sudeshkumar, Chakaravarthy Ezilarasan, Sivaprakasam Palani, Jayaseelan Veerasundaram, Modelling and Simulation of Machining Attributes in dry Turning of Aircraft Materials Nimonic C263 using CBN, Manufacturing Rev. 8, 30 (2021) 